\title{
93. The Variation of Chromosome-Number in Loxoblemmus arictulus, a Species of Grylloid Family.
}

\author{
By Kazuo Suzuki. \\ Botanical Institute, Faculty of Agriculture, Tokyo Imperial University, \\ Komaba, Tokyo. \\ (Comm. by C. Ishikawa, M.I.A., July 12; 1933.)
}

The variation of chromosome-number has been found in a wide range of animals and plants in recent years and its significance was discussed. Of the present species Honda (1926) mentions three kinds of variations in the spermatogonial chromosomes. These are as follows:-

A group, where he gives $4 \mathrm{~V}$-shaped chromosomes and 10 rods with an $\mathrm{X}$, making 15 in all; B group, where $5 \mathrm{~V}$-shaped chromosomes and 8 rods with an $\mathrm{X}$ are found, making in all 14 chromosomes, and in $\mathrm{C}$ group $6 \mathrm{~V}$-shaped chromosomes and 6 rods with an $\mathrm{X}$ are found, making the entire number 13.

In his preliminary note, Omachi (1927) described the group C of Honda as a derivation from the ordinary number.

A careful study of the chromosomes of the present species has revealed me the following fact which will be reported briefly.

Figures 1-6 are drawn from the chromosome groups of the spermatogonial cells. These show that the above three groups of the combinations of spermatogonial chromosomes as described by Honda are valid.

A careful observation of the same reveals us, however, that the chromosomes described by Omachi and Honda as V-shaped can conveniently be separated into two forms $\mathrm{V}$ and $J$, as I have pointed out in my previous paper (1932), which will make the combinations somewhat different.

In this sense the three groups of the chromosomes of the A group consist of 4 J's, 10 rods with an X, making the total number 15 (Fig. 3 ), in the $\mathrm{B}$ group, we have $4 \mathrm{~J}$ 's, $1 \mathrm{~V}, 8$ rods, with an $\mathrm{X}$, the total number being 14 (Fig. 2), and in the $\mathrm{C}$ group, $4 \mathrm{~J}$ 's, 2 V's, 6 rods with an $\mathrm{X}$, making the total number 13 (Fig. 1).

Beside these groups the writer has found another type of chromosomes among a certain line of insects which belong to the first generation of a cross between an "X-rayed male" and "an untreated and normal female." 
No. 7.] The Variation of Chromosome-Number in Loxoblemmus arictulus.

The males of this species belonging to the group $\mathrm{C}$ were exposed to X-rays under the following conditions :- $70 \mathrm{k} . \mathrm{v}, 3 \mathrm{~m} . \mathrm{a}$, target distance $30 \mathrm{c.m}$. and aluminium filter $1 \mathrm{~m} . \mathrm{m}$. thick, the length of exposure 15 minutes.

The males thus treated were crossed with untreated females, each pair being kept together and separate from others.

The chromosomes observed in the spermatogonial cells of the insects thus produced, which will be called the group $\mathrm{D}$, are fifteen in number which are as follows :- 4 J's, 2 V's, 2 micro V's, 6 rods with an $\mathrm{X}=15$ (Fig. 4, 5).

Other insects similarly produced gave a different number of chromosomes of the spermatogonial cells consisting of $4 \mathrm{~J}$ 's, $2 \mathrm{~V}$ 's, 1 micro V, 6 rods and an $\mathrm{X}$, making the total number of fourteen (Fig. 6), this will be called the group $E$.

The number of insects reared from the cross amounted to 32 males among which only two showed the condition described as D group, while 15 showed that of $\mathrm{E}$.

The results of the number and the shape of the chromosomes thus obtained among different groups as compared with those of the group $\mathrm{C}$, will be seen in the two tables, as follows:-

TABLE A.

\begin{tabular}{cc|c|c|c|c}
\hline & J. & V. & Rod. & X. \\
\hline Group A. & 4 & 0 & 10 & 1 \\
\hline " B. & 4 & 1 & 8 & 1 \\
\hline " C. & 4 & 2 & 6 & 1 \\
\hline
\end{tabular}

TABLE B.

\begin{tabular}{rr|c|c|c|c|c}
\hline & J. & V. & Rod. & mv. & X. \\
\cline { 1 - 6 } Group C. & 4 & 2 & 6 & 0 & 1 \\
\hline " D. & 4 & 2 & 6 & 2 & 1 \\
\hline " E. & 4 & 2 & 6 & 1 & 1 \\
\hline
\end{tabular}

It will be seen that in Table $\mathrm{A}$, the number of $\mathrm{J}$-shaped chromosomes is always constant, whereas that of $\mathrm{V}$ and rod-shaped chromosomes is variable.

In Table $\mathrm{B}$, the number of $\mathrm{J}, \mathrm{V}$, and rod-shaped chromosomes is constant while the micro- $V$ chromosomes vary between 1-2.

An interesting point about these variant groups is perhaps the appearance of the micro V's among the chromosomes of the insects thus treated, which so far was not observed in normal spermatogonial cells.

The present studies were carried out under the derection of Professor K. Miyake, to whom I wish to extend my profound thanks. 


\section{Literatures cited.}

H. Honda: The chromosome Numbers and the Multiple Chromosomes in Gryllinae. Proc. 2 (1926).

F. Omachi : Preliminary Note on Crytological studies on Grylloidea. Proc. 3 (1927).

K. Suzuki : Preliminary Note on the Chromosome Alterations by $\mathrm{x}$-rays in Loxoblemmus arictulus, a species of Grylloid Family. Proc. 8 (1932).

\section{Explanation of Plate.}

All the figures were drawn at the level of the desk on which the microscope was set with the aid of Abbe's drawing apparatus by using Zeiss objective $1 / 1_{2} \mathrm{~m} . \mathrm{m}$. and compensating occular, k. 12, tube length. $17 \mathrm{~m} . \mathrm{m}$.

Fig. 1. Group C.

Fig. 2. " B.

Fig. 3. " A.
Fig. 4-5. Group D.

Fig. $6 . \quad$ E.

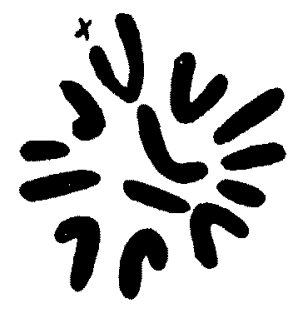

Fig 1.

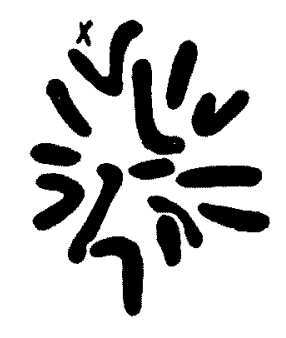

Fig. 2.

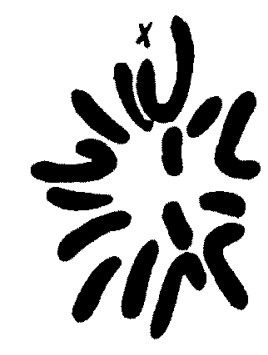

Fig. 3.

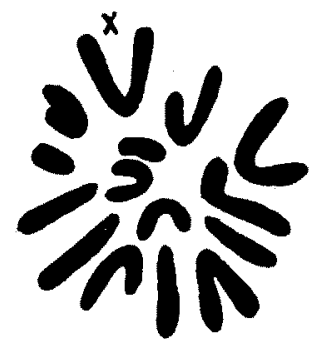

Fig. 4 .

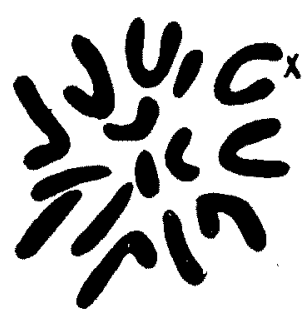

Fig. 5.

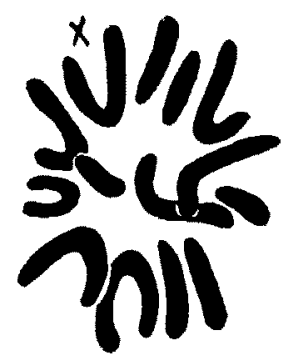

Fig. 6 . 